\title{
Inhaler Technique in Asthma: How Does It Relate to Patients' Preferences and Attitudes Toward Their Inhalers?
}

\author{
Lia Jahedi, MSc, ${ }^{1,2}$ Sue R. Downie, PhD, Bandana Saini, PhD, ${ }^{2,3}$ \\ Hak-Kim Chan, $\mathrm{PhD}^{2,4}$ and Sinthia Bosnic-Anticevich, $\mathrm{PhD}^{1,5,6}$
}

\begin{abstract}
Background: Correct inhaler technique can increase medication efficacy, reducing both dose and side effects. Patient preference for inhaler device has not been fully explored, and we hypothesized that if patients have a preference and can choose their inhaler, they might be more likely to use it correctly. Our aim was to determine the preferences, attitudes, and perceptions of patients with asthma toward their inhalers, and to evaluate whether any of these factors were related to inhalation technique.

Methods: Twenty-five patients with asthma (mean age 43.1 years) participated. Qualitative semi-structured interviews and quantitative patient satisfaction and preference questionnaires (PASAPQ) were used to explore patients' preferences, attitudes, and perceptions about their inhalers. Objective inhalation technique assessment was performed. Data were triangulated to identify characteristics that could indicate a relationship between inhaler technique, satisfaction, preference, and decision making.

Results: Themes from qualitative interviews were as follows: asthma inhalers and expectations; inhaler preference; characteristics of an ideal inhaler; perceived effectiveness of inhalers; and inhalers and patient decision making. PASAPQ scores indicated that all patients were at least "somewhat satisfied" with their inhalers, regardless of technique. Only $12 \%$ of inhalers were used correctly, despite pilot PASAPQ data suggesting that most patients were confident with their technique. The inhaler technique was unlikely to be related to satisfaction, perception of inhaler devices, or choice in device selection. Patients with correct inhaler technique were more aware of their asthma and expressed motivation to achieve optimal asthma control.

Conclusions: The majority of the asthmatic patients did not use their inhaler(s) correctly, despite most having confidence in their technique. Patients attributed confidence in their inhaler technique to their belief that their inhaler was effective. Most patients had not been involved in decision making about which inhalation device to use. These findings highlight the lack of understanding of the important role of correct inhaler technique in asthma management.
\end{abstract}

Keywords: asthma, inhaler technique, patient preference, perception

Introduction

ThHALE THERAPY Is the cornerstone of asthma treatment, and direct delivery of medication to the lung allows for optimal efficacy and safety. However, up to $94 \%$ of patients with asthma and COPD do not use their inhalers correctly, ${ }^{(1-5)}$ and they require multiple education sessions to maintain their technique. ${ }^{(6,7)}$ Pressurized metered dose inhalers (pMDIs) are

\footnotetext{
${ }^{1}$ Woolcock Institute of Medical Research, Glebe, Australia.

${ }^{2}$ Faculty of Pharmacy, University of Sydney, Sydney, Australia.

${ }^{3}$ The NHMRC Centre for Integrated Research and Understanding of Sleep (CIRUS), Glebe, Australia.

${ }^{4}$ Advanced Drug Delivery Group, Faculty of Pharmacy, University of Sydney, Sydney, Australia.

${ }^{5}$ Sydney Medical School, University of Sydney, Sydney, Australia.

${ }^{6}$ Sydney Local Health District, Sydney, Australia.
}

(C) Lia Jahedi, et al., 2016. Published by Mary Ann Liebert, Inc. This Open Access article is distributed under the terms of the Creative Commons Attribution Noncommercial License (http://creativecommons.org/licenses/by-nc/4.0/) which permits any noncommercial use, distribution, and reproduction in any medium, provided the original author(s) and the source are credited. 
the most commonly prescribed devices, ${ }^{(8)}$ but their correct use requires simultaneous device activation and inspiration, a challenge for many patients. ${ }^{(9)}$ In addition to coordination problems, elderly patients ${ }^{(10)}$ and patients with osteoarthritis ${ }^{(11)}$ or weak hands may not have the grip strength or dexterity needed to fire the inhaler. Although dry powder inhalers (DPIs) are breath activated and do not require the same coordination as pMDIs, more than $90 \%$ of patients fail to demonstrate the correct DPI inhalation technique. ${ }^{(12)}$ Actuating the DPI device is problematic for children, the elderly, and extremely breathless patients, who may not be able to achieve a fast and forceful enough inhalation to activate the device. Breathless patients may also not be able to maintain the 10 second breath-hold that is recommended immediately after inhalation. ${ }^{(13)}$ Poor inhalation technique may also be due to confusion if patients are using more than one type of inhaler. ${ }^{(14)}$ Considering all of these factors, patients with slow inspiratory flow (i.e., flow limitation) may be well suited to pMDIs if they can coordinate hand and breath maneuvers; whereas patients who can achieve an adequate inspiratory flow but who have problems with coordination may be better suited to DPIs. ${ }^{(15)}$

Aside from patients' issues, other factors contributing to poor inhalation technique include lack of knowledge of correct inhaler technique in healthcare professionals, ${ }^{(16,17)}$ and patient inhaler preference. There is a significant lack of understanding by primary healthcare professionals of the proper use of pMDIs. ${ }^{(18)}$ Pharmacists, who are the "last port of call" before patients attempt to self-administer medication, may also have a poor theoretical and practical knowledge of inhaler devices. ${ }^{(19)}$ Lenney et al. ${ }^{(20)}$ reported that when patients with airflow obstruction were offered a choice in inhaler type, the top four most preferred devices also achieved the best score for correct inhaler technique. Consequently, to maximize correct inhaler use, education of healthcare providers and a shared decisionmaking model, where the physician's prescription decision is based on patient preference, would be ideal strategies.

Our key research question is whether positive attitudes toward inhalers and use of "preferred" devices enhance inhaler technique. We believe this association is plausible given that previous research ${ }^{(21)}$ has demonstrated that patient perception of whether it is important to use an inhaler predicts both correct pMDI use and the motivation to keep practicing the correct inhaler technique. Motivation to use an inhaler correctly is also a significant predictor of the correct inhaler technique and results in fewer relapses to incorrect practices. ${ }^{(21)}$ However, few studies ${ }^{(22-24)}$ have specifically addressed the relationship between attitudes, perceptions, and inhalation technique, and filling this gap in knowledge could help broaden our understanding of what motivates and enables patients to user their inhaler devices correctly.

The aims of our study were to explore the attitudes, perceptions, and preferences of adults with asthma regarding inhaler devices, and their level of decision making in choosing their device(s). Second, we wanted to investigate whether these attitudes, perceptions, and preferences for inhaler devices were associated with inhaler technique. We hypothesized that if asthmatic patients have a formalized preference for their inhaler and have been involved in choosing it, they would be more likely to use it correctly. Moreover, if patients had positive attitudes and perceptions toward their inhaler device, and recognized the benefit of preventer medication, this would lead to greater device acceptance and, therefore, a better inhalation technique.

\section{Materials and Methods}

A mixed-model approach was used, and qualitative methods, namely semi-structured interviews, were employed to gain an insight into patient attitudes and preferences regarding their inhaler and level of autonomy in selecting devices. At these interviews, patients were asked to complete a quantitative questionnaire, and their inhaler technique was observed and scored against a validated checklist for their device(s). Data were triangulated from these mixed-model approaches.

\section{Patient recruitment and sample size}

A sample of pharmacies in Sydney were invited to participate in the study. Advertisements in participating pharmacies invited patients to approach the pharmacist about the study, and patients who presented a prescription for asthma medication were invited to participate in the study. Potential patients were referred to the researcher (LI), who then explained the study and organized a time for the study visit. This study was approved by the University of Sydney Human Research Ethics Committee (Protocol \#13501), and all patients completed written informed consent.

Inclusion criteria for patients were physician-diagnosed asthma, aged $\geq 18$ years, and currently using at least one inhaler device for their asthma. Exclusion criteria were inability to speak English, to self-complete the questionnaire, or to self-administer their inhaler.

After enrolment, a face-to-face interview was conducted with the patient in the pharmacy by the study researcher. Patients completed the patient satisfaction and preference questionnaire (PASAPQ), and they were asked to demonstrate to the researcher how they would usually use their inhaler(s).

Sample size for the qualitative data (semi-structured interview) was based on the sample required to reach saturation of data from the semi-structured interview. Data saturation occurs when no new thematic concepts emerge from the next patients being interviewed (i.e., new interviewees do not give any responses that have not already been given by previous interviewees).

\section{Semi-structured interview}

A semi-structured interview guide was developed based on published literature ${ }^{(25-27)}$ to explore the patients' preferences, attitudes, and perceptions of their inhalers specifically, and toward their asthma in general. The interviewee's own vocabularies were used when framing supplementary questions to uncover new areas without imposing any assumptions. ${ }^{(28)}$ After completion of initial interview questions, some questions were refined to ensure all targeted domains were covered. A summary of the key topics addressed and the questions included are shown in Supplementary Appendix S1 (Supplementary Data are available online at www.liebertpub.com/ jamp) of the online repository.

\section{$P A S A P Q$}

The PASAPQ is self-administrated, and it measures patient perception and preference for inhaler devices. ${ }^{(29)}$ It is validated for five domains; however, only three domains were relevant for this study. The 14 items of the PASAPQ that related to each domain were as follows: satisfaction with 
performance (7 items), satisfaction with convenience (6 items), and overall satisfaction (1 item). For each item within the three domains, a seven-point Likert scale was used. ${ }^{(29,30)}$

\section{Assessment of inhaler technique}

Validated checklists were used to objectively assess inhaler technique (Supplementary Appendix Tables S1-S5, online repository) and were developed from manufacturer instructions through an Australian Research Council grant LP 0882737. For Accuhalers, there were 10 key steps that had to be accurately performed for correct inhalation technique, 11 for Turbuhalers, 9 for pMDIs without spacer, 8 for pMDIs with spacer (single-breath technique), 7 for pMDIs with spacer (multiple-breath technique), and 9 for Autohalers. Patients were asked to demonstrate how they would usually use their inhaler(s), and they were assessed as having the "correct" technique only if they were able to perform all listed steps correctly on their first and only attempt. The total number of correct steps performed was modified to a score out of 10 , with a score of 10 representing all steps performed correctly (i.e., a score of 10 equals $100 \%$ of steps performed correctly). This normalized score was necessary to account for the difference in the number of steps assessed between the different types of inhaler devices.

\section{Data analysis}

Semi-structured interview. Analysis of the semi-structured interviews was carried out by two researchers independently, and agreement of results was achieved before finalization of themes and concepts. A deductive approach was used, based on the framework of asthma management and the role of medications (GINA $^{(31)}$ or the Asthma Management Handbook ${ }^{(32)}$ ) as well as empirical data articulated in the PASAPQ. Interviews were audio recorded and transcribed verbatim, and content analysis was performed to identify emerging concepts and themes. Open coding was used to break data into events, actions, interactions, and emotions that could be matched up for similarities and differences. These data were assigned conceptual labels and grouped together into categories and subcategories. ${ }^{(33)}$ The core concept was then captured from within these sub-categories and organized into themes.

PASAPQ. Each patient received a score for the domains of satisfaction with performance, satisfaction with convenience, and overall satisfaction, totaled from the seven-point Likert scale.

Assessment of inhalation technique. For each inhaler, patients were assessed as having either a correct (performed all steps correctly) or an incorrect (did not perform all steps correctly) technique. Patients also received an inhalation technique score, which reflected the number of steps performed correctly.

Triangulation of data. Data related to inhaler technique, satisfaction (PASAPQ) and qualitative data were triangulated. This was achieved by mapping data from the PASAPQ satisfaction domains, across the theme of the semi-structured interview within the framework of correct or incorrect inhaler technique. Triangulation was used as a method of validating the phenomenon being studied across the three data sources collected through three different research methods.

\section{Results}

Data saturation of thematic concepts from the semistructured interviews occurred within 20 interviews; however, data collection continued up to 25 interviews. Therefore, 25 patients completed the study, and their demographics are shown in Table 1 . The four types of asthma inhalers used by these patients were pMDI (92\% of patients), Turbuhaler (32\%), Accuhaler (20\%), and Autohaler (4\%).

\section{Semi-structured interview}

Five core themes emerged from the semi-structured interviews and are summarized next. Examples of quotations from patients that are relevant to each theme are shown in Table 2.

Asthma inhalers and expectations. Patients did not identify inhalers as mechanical delivery devices that were distinct from the medication itself. Rather, inhalers were part of the treatment process, and it was difficult for them to make the connection that effectiveness was related to the device or drug. Effectiveness of medication in relieving asthma symptoms was perceived as an indication of a good inhalation technique.

Patients felt dependent on their inhalers, experiencing discomfort and concern if they did not have their inhalers with them.

Prior experience of side effects and reported ineffectiveness of medication affected patients' overall thoughts about their inhalers. This contrasted with their positive experiences, where long-term device use resulted in satisfaction with the device and perceptions of ease of use.

Patients were dissatisfied that pMDIs lack a counter to track the number of doses given; however, many lacked knowledge and information about the availability of alternate inhalers. For others, the effectiveness of their inhalers

Table 1. Demographics of Asthmatic Patients

\begin{tabular}{lc}
\hline & $\mathrm{n}=25$ \\
\hline Age (years), mean $( \pm \mathrm{SD})$ & $43.08 \pm 15.5$ \\
Range (years) & $21-79$ \\
Female/Male $(n)$ & $19 / 6$ \\
Highest level of education, $n(\%)$ & $7(28)$ \\
Secondary school & $8(32)$ \\
Diploma or TAFE degree & $4(16)$ \\
University undergraduate degree & $6(24)$ \\
Postgraduate degree & $24.12 \pm 10.4$ \\
Duration of asthma (years), mean $( \pm \mathrm{SD})$ & $2-40$ years \\
Range (years) & \\
Preventer medication prescribed & 13 \\
Seretide $(n)$ & 5 \\
Symbicort $(n)$ & 2 \\
Pulmicort $(n)$ & 2 \\
Flixotide $(n)$ & \\
\hline
\end{tabular}

${ }^{\mathrm{a}}$ Four patients were not prescribed any inhaled corticosteroids, and one patient was taking Seretide and Flixotide.

$\mathrm{SD}$, standard deviation. 
Table 2. Attitudes of Patients Toward their Inhalers: Quotations from the Semi-Structured Interviews

\section{Core themes from semi-structured}

interviews

\author{
Patient ID \\ and device type
}

P13, uses pMDI

and

expectations

P7, uses pMDI

P22, uses pMDI and

Turbuhaler ${ }^{\circledR}$

P23, uses an Accuhaler ${ }^{\circledR}$,

Turbuhaler, and pMDI

P25, uses Turbuhaler

P24, uses pMDI

Inhaler P20, uses Turbuhaler

preference

P17, uses pMDI

P3, uses Accuhaler and pMDI

P25, uses Turbuhaler

P17, uses pMDI

P13, uses an Accuhaler

P22, uses Turbuhaler

Characteristics of P13, uses Accuhaler and an ideal inhaler pMDI

P24, uses pMDIs

P1, uses pMDIs

P12, uses pMDI

P25, uses Turbuhaler

Perceived effectiveness of inhalers
P13, uses an Accuhaler
and pMDI

P25, uses Turbuhaler

P20, uses pMDIs

P12, uses pMDI

P23, uses an Accuhaler, Turbuhaler, and pMDI
"I am getting results and for me the result is this, my asthma declines, my breathing is easier and also if I have some sort of congestion, it releases the congestion and actually clears my lungs... because it works, my technique must be good."

"My greatest concern is that I have to use it for the rest of my life."

"I would not be without it; I am very dependent on it. I would not go anywhere. If I go anywhere and I do not have it, I will be a bit nervous."

"I have been trying different things and then I end up using this one. Before, I had xxxx (a type of Turbuhaler). It was not good either. They all have something... I get anxiety reactions."

"I have used it all my life so am very comfortable with it. I know how to use it."

"You can feel the benefit of it which is important. So I really don't want to change it, you know. If I am getting comfort and relief from that, I think that is the main thing."

"Sometimes tough if you are suffering from asthma, you can't take a deep breath to inhale really deeply. With a good inhaler you have got to take a normal breath and it just goes in."

"I quite like the way that some of them now have the little numbers on it, so I know when it runs out instead of keep trying, when you realise that there is actually nothing left into it."

"I don't like xxxx (a type of pMDI) not being able to completely tell them when it runs out....dose counter would be better."

"It is easy to carry around. I travel quite a bit for work so it is not a big thing to carry around.",

"What I dislike is when I throw them in my bag and something gets caught in them and I go to use it and it goes to my lung... Things can go down inside it or if I lost the cap on the end, lots of funny things end up

from my handbag in there then end up down in my lungs."

"What do I like most about it is just the fact that it has got the mouthpiece covered up....the hygiene fact to it. That would be the positive thing."

"I never know whether I loaded it or not and I can be doing this and I don't know whether I am wasting it and it is expensive, very expensive."

"Easy to use...compliance because you have something you have to take it, particularly the steroid ones... If it is too hard, you do not take it and also just trying to remember to take it, linking that to something you do like brushing your teeth."

"Gauge on the Xxxx (a type of pMDI) would be a big advantage... I wouldn't like to be caught up without having something in the inhaler." "It would be lighter and smaller, the portability reasons."

"Keep it clean so nothing would get on top of it."

"If there was a way of monitoring the delivery of medication that wouldn't be a bad feature to have as well, just in terms of making ensuring.... For the people who have to monitor their asthma very carefully, method of monitoring the delivery of the medication would be useful to have as well."

"I am getting results and for me the result is the asthma declines, my breathing is easier and also if I have got some sort of congestion, it releases the congestion and actually enables me to clear the lungs... because it works my technique must be good."

"Whether I am getting the full dose I am not sure but certainly in terms of its effects, it seems to work well and I do not have an asthma attack for a long time so I have got no reason to doubt that I am not doing it correctly."

"Confident. I have been using them all my life so it's like blinking."

"It is something I have used probably for about 10 years so yes very confident. My technique is effective."

"I use it in the right way. The way the doctor showed me." 
TABle 2. (CONTINUED)

\begin{tabular}{|c|c|c|}
\hline $\begin{array}{l}\text { Core themes from } \\
\text { semi-structured } \\
\text { interviews }\end{array}$ & $\begin{array}{l}\text { Patient ID } \\
\text { and device type }\end{array}$ & Quotations \\
\hline \multirow{9}{*}{$\begin{array}{l}\text { Inhalers and } \\
\text { patient } \\
\text { decision } \\
\text { making }\end{array}$} & P20, uses pMDI & $\begin{array}{l}\text { "It is pretty much; I mean it's not like a science. Is it? Yeah open your } \\
\text { mouth and put your head back and take a couple of puffs and pretty } \\
\text { much, if I can do it, anyone can do it." }\end{array}$ \\
\hline & $\begin{array}{l}\text { P11, uses Turbuhaler and } \\
\text { pMDI }\end{array}$ & "I usually get the taste. I can taste the medication ... Yeah it has a certain \\
\hline & $\begin{array}{l}\text { P9, uses Accuhaler and } \\
\text { pMDI }\end{array}$ & "I am not sure if I am using them in the right way but yeah it is working." \\
\hline & P7, uses pMDIs & $\begin{array}{l}\text { "I don't mind using the inhalers. I can manage it pretty well. I prefer using } \\
\text { the spacer because I don't think I'll be comfortable just using the inhaler } \\
\text { by itself with my technique, so that's why I use it with the spacer." }\end{array}$ \\
\hline & $\begin{array}{l}\text { P21, uses an Accuhaler } \\
\text { and pMDI }\end{array}$ & $\begin{array}{l}\text { "No, I have always got the one doctor says, the doctor says take that I will } \\
\text { take that. I don't take away from that because I trust them after years." }\end{array}$ \\
\hline & P18, uses pMDI & $\begin{array}{l}\text { "I was just thinking, I would take the advice of my doctor because he has } \\
\text { an educated opinion.", }\end{array}$ \\
\hline & P25, uses Turbuhaler & $\begin{array}{l}\text { "The sort of the device I use is not that important to me, it is the effect it has } \\
\text { on me and the management of my condition is more important than how } \\
\text { it is administered." }\end{array}$ \\
\hline & $\begin{array}{l}\text { P13, uses an Accuhaler } \\
\text { and pMDI }\end{array}$ & $\begin{array}{l}\text { "It is not about the method of delivery for me. It's about delivery. It's about } \\
\text { what medication does." }\end{array}$ \\
\hline & P8, uses Turbuhaler & $\begin{array}{l}\text { "xxxx (a type of pMDI), I just wasn't getting any benefit from it because I } \\
\text { couldn't take it, I couldn't breathe at the right time and I found it really } \\
\text { uncomfortable to use and they told me xxxx (a type of Turbuhaler) they give } \\
\text { to children so I told them Ok I'll try that one and because it is very mild and } \\
\text { it's just exercise induced asthma then I don't need anything stronger." }\end{array}$ \\
\hline
\end{tabular}

pMDI, Pressurized metered dose inhaler.

in relieving asthma symptoms was adequate to convince them that they did not need to change inhalers.

Inhaler preference. Every patient wanted a device that was easy to use. pMDI users perceived that their devices were easy to use, whereas patients using DPIs reported that loading the dose was the most troublesome step for them, followed by concerns about the difficulty of inhaling a dose during an attack. Also of concern during asthma attacks was the lack of counter on most devices, which could lead to a shortage of medication when most needed.

Patients felt that smaller-sized inhalers are linked to improved adherence due to their portability. Other patients considered inhalers bulky and difficult to fit into a handbag or pocket.

Patients raised concerns about hygiene of pMDIs, since lids can come off easily and dust can build up in the nozzle, which may aggravate asthma during inhalation. Cleaning inhalers regularly was considered inconvenient, and DPIs were considered to be more hygienic than pMDIs.

Patients considered inhalers expensive, particularly preventers.

Characteristics of an ideal inhaler. Some patients had never considered what features they would like in an ideal inhaler, whereas others had clear opinions based on convenience and performance. Ease of use was important, since preventers are used daily, and relievers need to be easy to use during emergencies. The majority of patients believed that a dose counter should be an integral part of an inhaler.
Patients would prefer if their inhalers gave some feedback on their performance after use, to monitor the delivery of the medication to the lung.

Perceived effectiveness of inhalers. Most patients were confident with their inhaler technique, and this confidence was related to their perceived effectiveness of the medication rather than to any objective measure of technique. The fact that many of the patients had been using their inhalers for a long time made them confident that they were using them correctly.

Confidence in the inhaler technique was also attributed to initial technique training, perceived ease of use, and feeling the taste of medication in their mouth. The majority of patients emphasized the significance of proper training with a health professional. Only three patients expressed uncertainty about their inhaler technique, although they found their asthma treatment effective.

Inhalers and patient decision making. Very few patients were informed of the option of being involved in treatment decision making; however, they did not express dissatisfaction about this and conveyed a strong and trusting relationship with their physicians.

Patients did not believe that inhaler device selection played a significant role in asthma treatment or in achieving asthma control, and they thought that treatment decision making was largely influenced by patient history and side effects. Some patients mentioned that poor technique could be a reason for changing the inhaler device. 
Table 3. Inhalation Technique Results by Inhaler Type

\begin{tabular}{lccc}
\hline Device & $\begin{array}{c}\text { Number of } \\
\text { patients using } \\
\text { this inhaler }\end{array}$ & $\begin{array}{c}\text { Number of } \\
\text { patients demonstrating } \\
\text { correct technique } n(\%)\end{array}$ & $\begin{array}{c}\text { Mean } \\
\text { inhaler } \\
\text { score }( \pm S D)\end{array}$ \\
\hline pMDI & 22 & $2(9.1)$ & $7.2 \pm 1.9$ \\
pMDI + spacer single-breath technique & 3 & $1(33.3)$ & $7.9 \pm 2.6$ \\
pMDI + spacer multiple-breath technique & 1 & 0 & $8.6 \pm 0$ \\
Turbuhaler & 8 & 2 & $6.7 \pm 1.8$ \\
Accuhaler & 5 & 0 & $8.3 \pm 1.7$ \\
Autohaler & 1 & $5(12.5 \%)$ & $6.7 \pm 0$ \\
Total & 40 & & $7.4 \pm 1.9$ \\
\hline
\end{tabular}

\section{Inhalation technique}

Table 3 summarizes the proportion of patients demonstrating the correct inhaler technique for each device, and the mean inhalation technique scores. Overall, $87.5 \%$ of inhalers were used incorrectly.

\section{$P A S A P Q$}

Mean ( \pm standard deviation) overall PASAPQ scores for satisfaction with performance, satisfaction with convenience, and overall satisfaction were $41.4 \pm 6.2,34.7 \pm 4.9$, and $6 \pm 0.8$, respectively. Mean scores for each device are shown in Table 4.

Matrix A (Table 5) represents data from patients with correct inhaler technique, related to satisfaction domains from the PASAPQ triangulated with qualitative responses (exploring preference and decision making). Matrix B (Table 6) is for those patients with the incorrect inhaler technique.

Triangulation of inhaler technique and semi-structured interview responses with the pilot PASAPQ data showed that it was unlikely that there was a relationship between inhaler technique, satisfaction, perception of inhaler devices, and/or the opportunity for patients to have a choice in inhaler device selection. However, it was likely that there was an association between correct inhaler technique and patients who were more aware of their asthma and expressed motivation to achieve optimal control. This trend was seen through the relative qualitative data when separated for the patients with correct versus incorrect inhaler technique. PASAPQ scores and qualitative feedback related to satisfaction appeared consistent.

\section{Discussion}

In this study, we have evaluated the preferences, attitudes, and perceptions of patients with asthma toward a variety of inhaler devices, and the novelty of our study is that we have triangulated these data with inhalation technique assessment to determine whether the correct inhalation technique is related to patient preferences and attitudes. We found that the majority of the asthmatic patients in this study did not use their inhalers correctly. There was no relationship between inhaler technique and any of the following factors: patient perception of inhalers, satisfaction with inhalers, or having a choice in inhaler device selection. Rather, we found that patients intrinsically linked inhalation device use, selection, and preference to: medication effectiveness, overall views about asthma management, and belief and trust that their healthcare providers could make decisions about their medications for them. Therefore, factors unrelated to the device itself were influencing patients' opinions of their inhalers.

Most previous studies in this area have focused on quantitative approaches, ${ }^{(30,34-37)}$ whereas the strength of our study is the triangulation of both quantitative and qualitative data. Despite strong scientific evidence that inhalers as delivery devices are important in the clinical efficacy of medication, patients in this study were unaware of this, perhaps not having the information disseminated from their healthcare providers. Patients did not consider the physical characteristics of their inhalers as important for efficacy, nor did they distinguish the inhalation devices themselves from the specific medications that they delivered. Patient opinions were centered on perceptions of the effectiveness of their

Table 4. Mean PaSAPQ Scores for the Domains of Satisfaction with Performance, Satisfaction with Convenience, and Overall Satisfaction for Each Inhaler Device, AND For PATIENTS With CORRECT AND InCORRECT TeCHNIQUe

\begin{tabular}{|c|c|c|c|c|c|c|}
\hline$P A S A P Q$ score & $\begin{array}{c}p M D I \\
(\mathrm{n}=23)\end{array}$ & $\begin{array}{l}\text { Turbuhaler } \\
\quad(\mathrm{n}=8)\end{array}$ & $\begin{array}{c}\text { Accuhaler } \\
(\mathrm{n}=5)\end{array}$ & $\begin{array}{c}\text { Autohaler } \\
(\mathrm{n}=1)\end{array}$ & $\begin{array}{c}\text { Correct } \\
\text { Technique } \\
(\mathrm{n}=4)^{\mathrm{a}}\end{array}$ & $\begin{array}{c}\text { Incorrect } \\
\text { Technique } \\
(\mathrm{n}=33)^{\mathrm{a}}\end{array}$ \\
\hline Satisfaction with performance ${ }^{b}$ & $41.8 \pm 5.4$ & $40.3 \pm 6.4$ & $40.2 \pm 9.8$ & $48 \pm 0$ & $40.0 \pm 7.7$ & $41.6 \pm 6.1$ \\
\hline Satisfaction with convenience ${ }^{c}$ & $34.4 \pm 4.8$ & $36.5 \pm 4.1$ & $31.8 \pm 5.9$ & $41 \pm 0$ & $31.5 \pm 4.9$ & $35.1 \pm 4.8$ \\
\hline Overall satisfaction $^{\mathrm{d}}$ & $6.1 \pm 0.8$ & $6.12 \pm 0.9$ & $5.6 \pm 1.1$ & $7 \pm 0$ & $6.0 \pm 0.8$ & $6.1 \pm 0.9$ \\
\hline
\end{tabular}

Values are means \pm SD.

${ }^{a} n$ is smaller here than in Table 3, because a single PASAPQ score was given to cover the one device if patients used two or more of the same type of device.

bScore can range from 7 to 49 . Scores $\geq 35$ from Likert scale indicate at least "somewhat satisfied" and $\geq 42$ indicate at least "satisfied."

"Score can range from 6 to 42 . Scores $\geq 30$ from Likert scale indicate at least "somewhat satisfied" and $\geq 36$ indicate at least "satisfied."

"Score can range from 1 to 7 . Scores $\geq 5$ from Likert scale indicate at least "somewhat satisfied" and $\geq 6$ indicate at least "satisfied."

PASAPQ, patient satisfaction and preference questionnaires. 
Table 5. Matrix A-Triangulation of Data for Patients with Correct Inhaler Technique Related to Score From PASAPQ and Qualitative Feedback

\begin{tabular}{|c|c|c|c|c|c|}
\hline \multirow[b]{2}{*}{ Patient } & \multirow[b]{2}{*}{$\begin{array}{c}\text { Inhalation } \\
\text { device }\end{array}$} & \multicolumn{3}{|c|}{$P A S A P Q$ score } & \multirow[b]{2}{*}{ Qualitative feedback } \\
\hline & & $\begin{array}{l}\text { Satisfaction } \\
\text { with } \\
\text { performance }\end{array}$ & $\begin{array}{l}\text { Satisfaction } \\
\text { with } \\
\text { convenience }\end{array}$ & $\begin{array}{c}\text { Overall } \\
\text { satisfaction }\end{array}$ & \\
\hline Patient 4 & $\begin{array}{l}\text { pMDI and } \\
\text { pMDI }+ \\
\text { spacer }\end{array}$ & 41 & 34 & 6 & $\begin{array}{l}\text { Effectiveness of medication leads to satisfaction with } \\
\text { inhalers. } \\
\text { Satisfaction with asthma management and satisfaction } \\
\text { with inhalers } \\
\text { Some level of choice } \\
\text { Asthma control was important. }\end{array}$ \\
\hline Patient 13 & $\begin{array}{l}\text { pMDI } \\
\text { Accuhaler }\end{array}$ & $\begin{array}{l}40 \\
30\end{array}$ & $\begin{array}{l}29 \\
26\end{array}$ & $\begin{array}{l}6 \\
5\end{array}$ & $\begin{array}{l}\text { Confidence about technique because of effectiveness } \\
\text { of medication } \\
\text { Asthma control more important than type of inhaler } \\
\text { No involvement in treatment decision making }\end{array}$ \\
\hline Patient $21^{\mathrm{a}}$ & Accuhaler & 49 & 37 & 7 & $\begin{array}{l}\text { Overall dissatisfaction with asthma and medication } \\
\text { leads to dissatisfaction with inhalers. } \\
\text { Concern of taking medication and having asthma } \\
\text { Confidence about technique because of effectiveness } \\
\text { of medication } \\
\text { Could not distinguish device from medication } \\
\text { No involvement in treatment decision making }\end{array}$ \\
\hline
\end{tabular}

${ }^{\text {a}}$ Patient had two different inhaler devices, with correct technique for one and incorrect technique for the other.

treatment in relieving and controlling asthma symptoms, and the side effects experienced when using their inhalers.

Our finding that asthma control and side effects are significant factors in overall satisfaction with medication is consistent with the literature. ${ }^{(24,38)}$ Concern about side effects is a major factor contributing to poor adherence to asthma medication, ${ }^{(39,40)}$ highlighting the need for a deeper patient understanding that the correct inhaler technique can actually minimize side effects. Rectification of an incorrect inhaler technique may improve drug delivery, efficacy, and asthma control, ${ }^{(41)}$ allowing for the minimal effective dose of medication to be prescribed. Previous studies have also described a positive relationship between asthma control and satisfaction with medicine, ${ }^{(42,43)}$ emphasizing the benefit to patients in recognizing that the correct inhalation technique can achieve both asthma control and minimization of side effects, ultimately leading to greater satisfaction with medication.

In this study, patients reported that they were burdened by the chronic nature of their asthma and the requirement for using their inhalers in the long term, believing that having asthma puts them at risk of becoming dependent on their inhaler medications. The longer patients had been using their inhaler, the more confident and satisfied they were with it. However, it has been shown that using an inhaler for a long time actually increases the chance of the incorrect technique, particularly if no follow-up reassessment of inhaler technique is performed. ${ }^{(6,44)}$ None of the patients in the current study specifically reported ever having received follow-up inhaler device education (only initial instruction), possibly explaining their poor technique, and highlighting the need in both patients and health professionals for a greater recognition of the benefit of follow-up assessment in maintaining correct inhalation technique, which, in turn, could lead to improved asthma management.
If patients in the current study perceived that their inhaler was effective, they were overwhelmingly confident in their ability to use it. This confidence was somewhat misguided, since $88 \%$ of the devices used in this study were used incorrectly. This finding is consistent with the literature, ${ }^{(9,45,46)}$ emphasizing that patient perception of inhalation technique is not a reliable indicator of actual performance. Patients did not consider that with improved inhaler technique, they may achieve greater asthma control, decrease the dose of medication, and reduce potential side effects. In our study, the group with the correct inhaler technique displayed a greater awareness of asthma control and were motivated to optimize it. This is in keeping with a previous study that demonstrated that patients who were the most motivated to practice the correct inhaler technique were more likely to achieve it. ${ }^{(21)}$

Despite good evidence that shared treatment decision making and effective communication between patients and their medical practitioners benefits patients, ${ }^{(47,48)}$ the majority of patients in this study did not experience any level of involvement with treatment decision making. Adams et al. ${ }^{(49)}$ and Gibson et al. ${ }^{(50)}$ also reported preferences for patient autonomy in decision making in asthma, citing education level, cost concerns, and perceptions of the propensity of physicians to involve them in decisions as drivers for this choice. In the current study, lack of knowledge, insufficient physician time, and reliance on a trusted physician to make educated decisions were the main motivations for non-involvement. Caress et al. ${ }^{(51,52)}$ also found that although patients with asthma wanted their views respected, the majority did not want to take control of the decision making. Perhaps increasing both patient awareness of the option of shared treatment decision making and the time that physicians have available for their patients in the future 
Table 6. Matrix B-Triangulation of Data for Patients with Incorrect inhaler Technique Related to Score From PASAPQ and Qualitative FeEDback

\begin{tabular}{|c|c|c|c|c|c|}
\hline \multirow[b]{2}{*}{ Patient } & \multirow[b]{2}{*}{$\begin{array}{l}\text { Inhalation } \\
\text { device }\end{array}$} & \multicolumn{3}{|c|}{$P A S A P Q$ score } & \multirow[b]{2}{*}{ Qualitative feedback } \\
\hline & & $\begin{array}{l}\text { Satisfaction } \\
\quad \text { with } \\
\text { performance }\end{array}$ & $\begin{array}{l}\text { Satisfaction } \\
\text { with } \\
\text { convenience }\end{array}$ & $\begin{array}{l}\text { Overall } \\
\text { satisfaction }\end{array}$ & \\
\hline Patient 1 & pMDI & 33 & 28 & 6 & $\begin{array}{l}\text { Overall satisfaction with inhalers } \\
\text { Long-term usage leads to satisfaction. } \\
\text { Confidence of technique }\end{array}$ \\
\hline Patient 2 & pMDI & 44 & 32 & 5 & $\begin{array}{l}\text { Overall satisfaction with inhalers } \\
\text { Confidence of technique }\end{array}$ \\
\hline Patient 3 & $\begin{array}{l}\text { pMDI } \\
\text { Accuhaler }\end{array}$ & $\begin{array}{l}31 \\
29\end{array}$ & $\begin{array}{l}29 \\
25\end{array}$ & $\begin{array}{l}6 \\
4\end{array}$ & $\begin{array}{l}\text { Effectiveness leads to satisfaction with inhalers. } \\
\text { Effectiveness of medication leads to confidence of } \\
\text { technique. } \\
\text { Satisfaction with ease of use } \\
\text { Confidence of technique }\end{array}$ \\
\hline Patient 5 & $\begin{array}{l}\text { pMDI } \\
\text { Accuhaler }\end{array}$ & $\begin{array}{l}35 \\
48\end{array}$ & $\begin{array}{l}40 \\
41\end{array}$ & $\begin{array}{l}7 \\
7\end{array}$ & $\begin{array}{l}\text { Effectiveness of medication leads to confidence with } \\
\text { technique. } \\
\text { Difficult operation is reason for dissatisfaction with device. } \\
\text { Actual medication influences overall opinion of inhalers. } \\
\text { Confidence of technique with Autohaler }\end{array}$ \\
\hline Patient 6 & $\begin{array}{l}\text { pMDI } \\
\text { Turbuhaler }\end{array}$ & $\begin{array}{l}45 \\
45\end{array}$ & $\begin{array}{l}33 \\
40\end{array}$ & $\begin{array}{l}6 \\
7\end{array}$ & $\begin{array}{l}\text { Could not distinguish device from medication } \\
\text { Confidence with technique } \\
\text { Actual medication influences overall opinion of inhalers. } \\
\text { Satisfaction with convenience of Turbuhaler } \\
\text { No involvement in treatment decision making }\end{array}$ \\
\hline Patient 7 & $\begin{array}{l}\text { pMDI }+ \\
\text { spacer }\end{array}$ & 440 & 428 & 44 & $\begin{array}{l}\text { Not confident of technique without spacer } \\
\text { Overall dissatisfaction with having asthma and necessity } \\
\text { of using inhalers } \\
\text { Dissatisfaction with convenience of device } \\
\text { Actual medication influences overall opinion of device. }\end{array}$ \\
\hline Patient 8 & Turbuhaler & 47 & 39 & 7 & $\begin{array}{l}\text { Effectiveness of medication leads to satisfaction with } \\
\text { inhalers. } \\
\text { Effectiveness of medication leads to confidence with } \\
\text { technique. } \\
\text { Satisfaction with inhalers because of easy performance } \\
\text { Some level of involvement in treatment decision making }\end{array}$ \\
\hline Patient 9 & $\begin{array}{l}\text { pMDI } \\
\text { Accuhaler }\end{array}$ & $\begin{array}{l}49 \\
48\end{array}$ & $\begin{array}{l}32 \\
34\end{array}$ & $\begin{array}{l}6 \\
6\end{array}$ & $\begin{array}{l}\text { Not very confident about technique } \\
\text { Effectiveness of medication leads to some level of } \\
\text { confidence about technique. } \\
\text { No involvement in treatment decision making }\end{array}$ \\
\hline Patient 10 & pMDI & 41 & 36 & 6 & $\begin{array}{l}\text { Effectiveness of medication leads to satisfaction with } \\
\text { inhalers. }\end{array}$ \\
\hline & Turbuhaler & 28 & 28 & 6 & $\begin{array}{l}\text { Could not distinguish device from medication } \\
\text { Dissatisfaction with operation of Turbuhaler, not confident } \\
\text { with technique } \\
\text { Confidence in technique with pMDI because of ease of use }\end{array}$ \\
\hline Patient 11 & $\begin{array}{l}\text { pMDI } \\
\text { Turbuhaler }\end{array}$ & $\begin{array}{l}33 \\
40\end{array}$ & $\begin{array}{l}29 \\
33\end{array}$ & $\begin{array}{l}5 \\
6\end{array}$ & $\begin{array}{l}\text { Long-term use leads to confidence with technique. } \\
\text { Could not distinguish device from medication } \\
\text { Effectiveness is the most important inhaler feature. } \\
\text { Effectiveness of medication leads to satisfaction with } \\
\text { inhalers. }\end{array}$ \\
\hline Patient 12 & pMDI & 46 & 39 & 7 & $\begin{array}{l}\text { Long-term use leads to confidence with technique. } \\
\text { Satisfied with operation of inhalers }\end{array}$ \\
\hline Patient 14 & pMDI & 47 & 38 & 7 & $\begin{array}{l}\text { Effectiveness of medication and long-term use lead to } \\
\text { satisfaction with inhalers. } \\
\text { Long-term use leads to confidence with technique. } \\
\text { Effectiveness of medication leads to confidence with } \\
\text { technique. } \\
\text { Satisfaction with operation leads to confidence with } \\
\text { technique. } \\
\text { Could not distinguish device from medication }\end{array}$ \\
\hline Patient 15 & pMDI & 45 & 39 & 6 & $\begin{array}{l}\text { Long-term use leads to satisfaction. } \\
\text { Effectiveness of medication leads to confidence about } \\
\text { technique. } \\
\text { Overall satisfaction with inhalers } \\
\text { Could not distinguish device from medication }\end{array}$ \\
\hline
\end{tabular}


TABle 6. (Continued)

\begin{tabular}{|c|c|c|c|c|c|}
\hline \multirow[b]{2}{*}{ Patient } & \multirow[b]{2}{*}{$\begin{array}{l}\text { Inhalation } \\
\text { device }\end{array}$} & \multicolumn{3}{|c|}{$P A S A P Q$ score } & \multirow[b]{2}{*}{ Qualitative feedback } \\
\hline & & $\begin{array}{l}\text { Satisfaction } \\
\quad \text { with } \\
\text { performance }\end{array}$ & $\begin{array}{l}\text { Satisfaction } \\
\quad \text { with } \\
\text { convenience }\end{array}$ & $\begin{array}{l}\text { Overall } \\
\text { satisfaction }\end{array}$ & \\
\hline Patient 16 & $\begin{array}{l}\text { pMDI and } \\
\text { pMDI }+ \\
\text { spacer }\end{array}$ & 38 & 35 & 6 & $\begin{array}{l}\text { Confidence about inhalation technique } \\
\text { Effectiveness of medication leads to satisfaction with } \\
\text { inhalers. } \\
\text { Satisfaction with operation leads to satisfaction with } \\
\text { inhalers. }\end{array}$ \\
\hline Patient 17 & pMDI & 42 & 37 & 6 & $\begin{array}{l}\text { Confidence about inhalation technique because of doctor's } \\
\text { satisfaction with technique } \\
\text { Could not distinguish device from medication }\end{array}$ \\
\hline Patient 18 & pMDI & 36 & 25 & 5 & $\begin{array}{l}\text { Overall dissatisfaction of having asthma affects the } \\
\text { opinion of inhalers. } \\
\text { Effectiveness of medication and long-term use leads to } \\
\text { confidence about technique. }\end{array}$ \\
\hline Patient 19 & $\begin{array}{l}\text { pMDI } \\
\text { Turbuhaler }\end{array}$ & $\begin{array}{l}49 \\
37\end{array}$ & $\begin{array}{l}42 \\
40\end{array}$ & $\begin{array}{l}7 \\
6\end{array}$ & $\begin{array}{l}\text { Long-term use leads to confidence about technique. } \\
\text { Could not distinguish device from medication } \\
\text { Long-term use leads to satisfaction with inhalers. } \\
\text { Satisfaction with inhalers because of satisfaction with } \\
\text { performance }\end{array}$ \\
\hline Patient 20 & pMDI & 49 & 39 & 7 & $\begin{array}{l}\text { Effectiveness of medication and long-term use leads to } \\
\text { confidence about technique. } \\
\text { Could not distinguish device from medication } \\
\text { Overall satisfaction with inhalers }\end{array}$ \\
\hline Patient $21^{\mathrm{a}}$ & pMDI & 45 & 39 & 7 & $\begin{array}{l}\text { Overall dissatisfaction with asthma and medication lead to } \\
\text { dissatisfaction with inhalers. } \\
\text { Confidence about technique because of effectiveness of } \\
\text { medication } \\
\text { Could not distinguish device from medication }\end{array}$ \\
\hline Patient 22 & pMDI & 46 & 31 & 7 & Long-term use leads to satisfaction with inhalers. \\
\hline Patient 23 & $\begin{array}{l}\text { Turbuhaler } \\
\text { pMDI }\end{array}$ & $\begin{array}{l}46 \\
41\end{array}$ & $\begin{array}{l}36 \\
40\end{array}$ & $\begin{array}{l}7 \\
7\end{array}$ & $\begin{array}{l}\text { Satisfaction with inhalers because of ease of use } \\
\text { Could not distinguish device from medication }\end{array}$ \\
\hline & Turbuhaler & 36 & 37 & 4 & $\begin{array}{l}\text { Confidence about technique because of effectiveness of } \\
\text { medication }\end{array}$ \\
\hline & Accuhaler & 45 & 37 & 6 & $\begin{array}{l}\text { Satisfaction/dissatisfaction with medication influences } \\
\text { opinion of device. }\end{array}$ \\
\hline Patient 24 & $\begin{array}{l}\text { pMDI and } \\
\text { pMDI + } \\
\text { spacer }\end{array}$ & 46 & 37 & 6 & $\begin{array}{l}\text { Confidence about technique because of effectiveness of } \\
\text { medication }\end{array}$ \\
\hline Patient 25 & Turbuhaler & 43 & 39 & 6 & $\begin{array}{l}\text { Effectiveness of medication leads to confidence about } \\
\text { technique. } \\
\text { Effectiveness of medication leads to satisfaction with } \\
\text { inhalers. }\end{array}$ \\
\hline
\end{tabular}

${ }^{\mathrm{a}}$ Patient had two different inhaler devices, with correct technique for one and incorrect technique for the other.

could aid in reducing the barriers to greater involvement in treatment decision making for patients with asthma.

Both our qualitative (semi-structured interview) and quantitative (PASAPQ) assessments of patient perception of inhalers were consistent in revealing that the majority of patients were satisfied with their inhalers. Ease of use was considered by patients as the most important feature of their inhaler, irrespective of device type. Patients associated ease of use with better handling of the device, effectiveness in controlling symptoms, and satisfaction and fulfilment with therapy. Patients reported pMDIs as being easy to use, even though it is well known that coordination of actuation and inhalation is one of the most challenging steps, being performed incorrectly by most patients. ${ }^{(9,53)}$ Despite the satisfaction with ease of use of DPIs, a number of patients were confused about the performance of their device and loading the dose, with some reporting that they could not feel anything coming out of the inhaler. Our patients stated that an ideal inhaler should have a dose counter to ease their concern of running out of medication, and it should be portable and hygienic. Overall, our findings are consistent with other published literature that rate ease of use, hygiene, inclusion of a metered dose counter, portability, and clear leaflet instruction as the most desirable inhaler features from the patients' perspective. ${ }^{(36,54,55)}$

We acknowledge that not having a measure of asthma control is a potential limitation of this study. It would be valuable to compare patient views on medication effectiveness with an objective measure of asthma control, and the inclusion of other specific methods such as discrete choice experiments and collection of adherence data may have helped elicit additional patient preference and attitudes toward their inhalers in their real-life setting.

In summary, our finding that the correct inhalation technique is not related to either patient perception or involvement with decision making, and is unlikely to be related to satisfaction 
with medication, is in contrast to previous literature related to patient preference. The fact that patients could not differentiate the device from the medication itself is a novel finding, and it almost certainly influenced their ultimate perception about inhalers. Other factors unrelated to the device itself influenced the patients' perceptions of their device(s). There was a clear mismatch between the patients' inhalation technique and their perception of their inhalation technique, and satisfaction with the device was unlikely to be related to a better inhalation technique. Rather, those patients who were more aware, knowledgeable, or motivated to achieve good asthma control were more likely to have the correct inhalation technique.

Patients were generally not involved in treatment decision making, nor did they express an interest in being more actively involved. Possible barriers to a shared decision making were revealed, such as cost and physician lack of time. There was no indication that giving patients a choice in device selection would make a difference to the way they perceive their inhalers or their ability to use them correctly. Emphasizing that the correct inhalation technique can lead to better asthma control, reduce cost and side effects of medication, and lead to better outcomes for patients may provide some motivation for patients and healthcare professionals alike to focus on inhalation devices and technique. Since the overwhelming majority of patients in this study did not have the correct inhalation technique, perhaps adopting a more shared decision-making strategy may have the added benefit of providing opportunities for dialog and education between physician and patient about inhalation devices, and follow-up assessment of inhalation technique.

\section{Acknowledgments}

The authors would like to acknowledge the time and effort given by the patients who were involved in this study and the pharmacists who helped recruit them into the study.

\section{Author Disclosure Statement}

L.J., S.R.D., B.S., and K.C. declare that no conflicts of interest exist. S.B.-A.: Scientific and advisory boards: MEDA, Teva. Consultation: Mundipharma, GSK. No conflict of interest exists with these relationships and the research conducted in this study.

\section{References}

1. van Beerendonk I, Mesters I, Mudde AN, and Tan TD: Assessment of the inhalation technique in outpatients with asthma or chronic obstructive pulmonary disease using a metered-dose inhaler or dry powder device. J Asthma. 1998; 35:273-279.

2. Baqai HZ, Saleem MA, and Abair-ul-Haq M: Assessment of metered dose inhaler technique in patients with chronic lung disease at government hospitals of Rawalpindi. J Ayub Med Coll Abbottabad. 2011;23:37-39.

3. Lavorini F, Magnan A, Dubus JC, Voshaar T, Corbetta L, Broeders M, Dekhuijzen R, Sanchis J, Viejo JL, Barnes P, Corrigan C, Levy M, and Crompton GK: Effect of incorrect use of dry powder inhalers on management of patients with asthma and COPD. Respir Med. 2008;102:593-604.

4. Cochrane MG, Bala MV, Downs KE, Mauskopf J, and Ben-Joseph RH: Inhaled corticosteroids for asthma therapy:
Patient compliance, devices, and inhalation technique. Chest. 2000;117:542-550.

5. Rootmensen GN, van Keimpema AR, Jansen HM, and de Haan RJ: Predictors of incorrect inhalation technique in patients with asthma or COPD: A study using a validated videotaped scoring method. J Aerosol Med Pulm Drug Deliv. 2010;23:323-328.

6. Basheti IA, Armour CL, Bosnic-Anticevich SZ, and Reddel HK: Evaluation of a novel educational strategy, including inhaler-based reminder labels, to improve asthma inhaler technique. Patient Educ Couns. 2008;72:26-33.

7. Basheti IA, Armour CL, Reddel HK, and Bosnic-Anticevich SZ: Long-term maintenance of pharmacists' inhaler technique demonstration skills. Am J Pharm Educ. 2009;73:32.

8. Virchow JC, Crompton GK, Dal Negro R, Pedersen S, Magnan A, Seidenberg J, and Barnes PJ: Importance of inhaler devices in the management of airway disease. Respir Med. 2008;102:10-19.

9. Giraud V and Roche N: Misuse of corticosteroid metereddose inhaler is associated with decreased asthma stability. Eur Respir J. 2002;19:246-251.

10. Armitage JM and Williams SJ: Inhaler technique in the elderly. Age Ageing. 1988;17:275-278.

11. Australia NAC: Australian Asthma Handbook, Vol Version 1.1. National Asthma Council Australia, Melbourne, 2015, pg. 23.

12. Nimmo CJ, Chen DN, Martinusen SM, Ustad TL, and Ostrow DN: Assessment of patient acceptance and inhalation technique of a pressurized aerosol inhaler and two breathactuated devices. Ann Pharmacother. 1993;27:922-927.

13. Newman SP, Pavia D, Garland N, and Clarke SW: Effects of various inhalation modes on the deposition of radioactive pressurized aerosols. Eur J Respir Dis Suppl. 1982;119: 57-65.

14. van der Palen J, Klein JJ, van Herwaarden CL, Zielhuis GA, and Seydel ER: Multiple inhalers confuse asthma patients. Eur Respir J. 1999;14:1034-1037.

15. Capstick TG and Clifton IJ: Inhaler technique and training in people with chronic obstructive pulmonary disease and asthma. Expert Rev Respir Med. 2012;6:91-101; quiz 102-103.

16. Nguyen BN, Wainwright C, Basheti IA, Willis M, and Bosnic-Anticevich S: Do health professionals on respiratory wards know how to use inhalers? J Pharm Pract Res. 2010; 40:211-216.

17. Tsang KW, Lam WK, Ip M, Kou M, Yam L, Lam B, Cheung M, Lauder IJ, and Kumana CR: Inability of physicians to use metered-dose inhalers. J Asthma. 1997;34:493-498.

18. Interiano B, and Guntupalli KK: Metered-dose inhalers. Do health care providers know what to teach? Arch Intern Med. 1993;153:81-85.

19. Kesten S, Zive K, and Chapman KR: Pharmacist knowledge and ability to use inhaled medication delivery systems. Chest. 1993;104:1737-1742.

20. Lenney J, Innes JA, and Crompton GK: Inappropriate inhaler use: assessment of use and patient preference of seven inhalation devices. EDICI. Respir Med. 2000;94:496-500.

21. Ovchinikova L, Smith L, and Bosnic-Anticevich S: Inhaler technique maintenance: Gaining an understanding from the patient's perspective. J Asthma. 2011;48:616-624.

22. Serra-Batlles J, Plaza V, Badiola C, and Morejon E: Patient perception and acceptability of multidose dry powder inhalers: A randomized crossover comparison of Diskus/Accuhaler with Turbuhaler. J Aerosol Med. 2002; 15:59-64. 
23. Papi A, Haughney J, Virchow JC, Roche N, Palkonen S, and Price D: Inhaler devices for asthma: A call for action in a neglected field. Eur Respir J. 2011;37:982-985.

24. Price D, Harrow B, Small M, Pike J, and Higgins V: Establishing the relationship of inhaler satisfaction, treatment adherence, and patient outcomes: A prospective, realworld, cross-sectional survey of US adult asthma patients and physicians. World Allergy Organ J. 2015;8:26.

25. Cross S: Asthma inhalation delivery systems: the patient's viewpoint. J Aerosol Med. 2001;14 Suppl 1:S3-S7.

26. Giner J, Torrejon M, Ramos A, Casan P, Granel C, Plaza V, Belda J, and Sanchis J: [Patient preference in the choice of dry powder inhalers]. Arch Bronconeumol. 2004;40:106-109.

27. Anderson P: Patient preference for and satisfaction with inhaler devices. Eur Respir Rev. 2005;14:109-116.

28. Britten N: Qualitative interviews in medical research. BMJ. 1995;311:251-253.

29. Kozma CM, Slaton TL, Monz BU, Hodder R, and Reese PR: Development and validation of a patient satisfaction and preference questionnaire for inhalation devices. Treat Respir Med. 2005;4:41-52.

30. Hodder R, Reese PR, and Slaton T: Asthma patients prefer Respimat Soft Mist Inhaler to Turbuhaler. Int J Chron Obstruct Pulmon Dis. 2009;4:225-232.

31. (GINA) GIfA. Global Strategy for Asthma Management and Prevention. Global Initiative for Asthma. 2015, pgs. 29-38.

32. Australia NAC: Australian Asthma Handbook-Quick Reference Guide. Vol Version 1.0. National Asthma Council of Australia, South Melbourne, Australia. 2014, pgs. 11-13.

33. Brod M, Tesler LE, and Christensen TL: Qualitative research and content validity: Developing best practices based on science and experience. Qual Life Res. 2009;18:1263-1278.

34. Welch MJ, Nelson HS, Shapiro G, Bensch GW, Sokol WN, Smith JA, and Parasuraman BM: Comparison of patient preference and ease of teaching inhaler technique for Pulmicort Turbuhaler versus pressurized metered-dose inhalers. J Aerosol Med. 2004;17:129-139.

35. van der Palen J, Klein JJ, and Schildkamp AM: Comparison of a new multidose powder inhaler (Diskus/Accuhaler) and the Turbuhaler regarding preference and ease of use. $\mathrm{J}$ Asthma. 1998;35:147-152.

36. Mahajan P, and Okamoto L: Patient satisfaction with the Diskhaler and the Diskus inhaler, a new multidose power delivery system for the treatment of asthma. Clin Ther. 1997;19:1126-1134.

37. Sheth K, Bernstein JA, Lincourt WR, Merchant KK, Edwards LD, Crim CC, and Dorinsky PM: Patient perceptions of an inhaled asthma medication administered as an inhalation powder via the Diskus or as an inhalation aerosol via a metereddose inhaler. Ann Allergy Asthma Immunol. 2003;91:55-60.

38. Basyigit I, Yildiz F, Buyukgoze B, Yildirim E, and Bulut $O$ : Evaluation of treatment satisfaction in asthmatics. Turkish Respir J. 2006;7:6-9.

39. Al-Jahdali HH, Al-Zahrani AI, Al-Otaibi ST, Hassan IS, Al-Moamary MS, Al-Duhaim AS, Al-Shimemeri AA, and Al-Dawood AS: Perception of the role of inhaled corticosteroids and factors affecting compliance among asthmatic adult patients. Saudi Med J. 2007;28:569-573.

40. Boulet LP: Perception of the role and potential side effects of inhaled corticosteroids among asthmatic patients. Chest. 1998;113:587-592.

41. Basheti IA, Reddel HK, Armour CL, and BosnicAnticevich SZ: Improved asthma outcomes with a simple inhaler technique intervention by community pharmacists. J Allergy Clin Immunol. 2007;119:1537-1538.

42. Narayanan S, Edelman JM, Berger ML, and Markson LE: Asthma control and patient satisfaction among early pediatric users of montelukast. J Asthma. 2002;39:757-765.

43. Manap RA, Loh LC, Ismail TS, Muttalif AR, Simon GK, Toh RB, Norhaya MR, Tarekh NA, Hashim CW, Rani MF, and Mahayiddin AA: Satisfaction levels and asthma control amongst Malaysian asthmatic patients on budesonide/formoterol maintenance and reliever therapy: Experience in a real-life setting. Patient Relat Outcome Meas. 2012;3:71-78.

44. Sadowski CA, Cor K, Cave A, and Banh HL: Administration technique and acceptance of inhaler devices in patients with asthma or COPD. Ann Pharmacother. 2015;49:639-648.

45. Ho SF, OMahony MS, Steward JA, Breay P, and Burr ML: Inhaler technique in older people in the community. Age Ageing. 2004;33:185-188.

46. Micallef LA: A review of the metered dose inhaler technique in asthmatic and COPD patients. Malta Med J. 2015;27:22-28.

47. Wilson SR, Strub P, Buist AS, Knowles SB, Lavori PW, Lapidus J, and Vollmer WM: Shared treatment decision making improves adherence and outcomes in poorly controlled asthma. Am J Respir Crit Care Med. 2010;181:566-577.

48. Zolnierek KB, and Dimatteo MR: Physician communication and patient adherence to treatment: A meta-analysis. Med Care. 2009;47:826-834.

49. Adams RJ, Smith BJ, and Ruffin RE: Patient preferences for autonomy in decision making in asthma management. Thorax. 2001;56:126-132.

50. Gibson PG, Talbot PI, and Toneguzzi RC: Self-management, autonomy, and quality of life in asthma. Population Medicine Group 91C. Chest. 1995;107:1003-1008.

51. Caress AL, Beaver K, Luker K, Campbell M, and Woodcock A: Involvement in treatment decisions: What do adults with asthma want and what do they get? Results of a cross sectional survey. Thorax. 2005;60:199-205.

52. Caress AL, Luker K, Woodcock A, and Beaver K: A qualitative exploration of treatment decision-making role preference in adult asthma patients. Health Expect. 2002;5:223-235.

53. Crompton GK: Problems patients have using pressurized aerosol inhalers. Eur J Respir Dis Suppl. 1982;119:101-104.

54. Van Der Palen J, Eijsvogel MM, Kuipers BF, Schipper M, and Vermue NA: Comparison of the Diskus inhaler and the Handihaler regarding preference and ease of use. J Aerosol Med. 2007;20:38-44.

55. Schlaeppi M, Edwards K, Fuller RW, and Sharma R: Patient perception of the diskus inhaler: A comparison with the turbuhaler inhaler. Br J Clin Pract. 1996;50:14-19.

Received on January 5, 2016 in final form, April 28, 2016

Reviewed by: Federico Lavorini David Price

Address correspondence to: Sinthia Bosnic-Anticevich, PhD Woolcock Institute of Medical Research Glebe, NSW 2037 Australia

E-mail: sinthia.bosnic-anticevich@sydney.edu.au 